\title{
Produção de Material Instrucional para o Ensino de História da Paraíba
}

\author{
Diego R. S. Silveira ${ }^{1}$, Thaíse K. L. Costa ${ }^{1}$ \\ ${ }^{1}$ Departamento de Ciências Exatas - Centro de Ciências Aplicadas e Educação - \\ Universidade Federal da Paraíba(UFPB) - João Pessoa, PB - Brazil \\ diego.silveira@dcx.ufpb.br, thaise@dcx.ufp.b.br
}

\begin{abstract}
Interactive animations can be used in the educational support of History. They can help students with difficulty in abstracting concepts. This article describes the steps for the production of an interactive animation aimed at teaching History of Paraiba, as well as its application with elementary school students. The use of animations can stimulate cognitive processes such as perception, memory, language and thought. The interaction, combined with content-related challenges, allows attention focused on specific content. Based on the application of animation in the classroom, the potential of this material is observed as a resource to support the teaching of History, stimulating the participation and curiosity of students about the theme.
\end{abstract}

Resumo. Animações interativas podem ser utilizadas no apoio educacional de História e auxiliar alunos com dificuldade em abstrair conceitos. Este artigo descreve a visão geral da construção de uma animação interativa voltada ao ensino de História da Paraíba, bem como sua aplicação com alunos de ensino fundamental. Seu uso pode estimular processos cognitivos como percepção, memória, linguagem e pensamento. A interação, combinada a desafios relacionados ao conteúdo, permite uma atenção focada em partes específicas de assuntos. Com base na aplicação da animação em sala de aula, observa-se o potencial desse material como recurso de apoio ao ensino de História, estimulando a participação e curiosidade dos alunos acerca do tema.

\section{Introdução}

Em sala de aula, há crianças que expressam dificuldade em compreender fatos explicados verbalmente pelo professor, ou apenas pelas leituras de textos [Abusamra et al. 2008]. Quando se trata de recortes específicos da História, a exemplo da História da Paraíba, esse processo educacional pode ser ainda dificultado pela escassez de materiais acessíveis para os alunos. Assim, a elaboração de materiais instrucionais pode orientar estudantes e oferecer recursos que promovam uma melhor visualização, imersão e compreensão do conteúdo a ser estudado.

Nesse sentido, as animações interativas vêm conquistando cada vez mais espaço no cenário educacional atual, pois permitem aos alunos um olhar diferenciado, rico em detalhes e ponto de vista a partir de outras perspectivas, onde é possível controlar a velocidade do seu avanço, auxiliando a compreensão do conteúdo [Oliveira 2017][Tversky, Morrison e Betrancourt 2002]. As animações interativas são 
ferramentas de representação gráfica de objetos, personagens e cenários que representam uma sequência de fatos em ordem cronológica, tornando possível a visualização temporal dos fatos, estimulando a criatividade e imaginação dos usuários [Tavares 2005][Schimiguel et al. 2013].

Trabalhos nessa linha podem explorar as informações históricas de diferentes formas e apresentar histórias que estimulam e facilitam a compreensão do aluno em diversos aspectos, como geográficos, sociais e históricos linearmente dependentes de uma ordem cronológica [Memórias Reveladas 2010][ Secretaria de Educação do Pará. 2020]. No entanto, há ainda escassez de materiais interativos que exploram histórias para o público infantil [da Cruz Alves et al. 2016]. Além disso, em relação à História da Paraíba, não há registros de animações interativas que contenham a história contada de maneira lúdica, ressaltando fatos, batalhas e curiosidades que poderiam ser explorados pelo professor do ensino fundamental.

Nesse sentido, o artigo apresenta a visão geral do desenvolvimento e a experiência inicial de aplicação de uma animação interativa que auxilia professores e alunos do ensino fundamental no processo de ensino-aprendizagem de História da Paraíba, verificando o potencial motivacional desse recurso para suporte a aprendizagem. Assim, o artigo é dividido em 5 seções. A segunda seção mostra alguns trabalhos correlatos e diferenças do contexto do atual trabalho, a terceira seção apresenta os passos para o desenvolvimento da animação interativa acerca da História da Paraíba, a quarta mostra resultados iniciais de sua aplicação com estudantes de ensino fundamental e a quinta seção apresenta as considerações finais e trabalhos futuros.

\section{Uso da animação interativa para auxílio ao ensino e aprendizagem}

As animações interativas podem ajudar os discentes na absorção e retenção de conteúdo, pois a partir do momento em que o aluno passa a interagir com o recurso, ele deixa de ser apenas um espectador. A combinação de recursos interativos e animações torna o processo de aprendizagem mais atrativo, pois pode estimular a superação das dificuldades de percepção e compreensão. A possibilidade de iniciar, parar e reiniciar uma animação pode permitir uma melhor observação focada em uma parte específica do tema [Tavares 2005].

De acordo com Xiao (2013), as animações em sala de aula podem ser classificadas em três tipos principais: (i) expositivas, quando os usuários assistem ao conteúdo expositivo em telas; (ii) interativas, quando os usuários podem interagir com o conteúdo em um nível superior; (iii) quizzes, quando os usuários são testados em um conteúdo específico. Neste sentido, há diferentes formas de explorar o uso dessas mídias no processo educacional.

Com foco no apoio ao ensino-aprendizagem de História pode-se citar animações como "A Guerrilha do Araguaia" e "A guerra do século 20". A animação interativa "A Guerrilha do Araguaia" [Memórias Reveladas 2010] contém diversos recursos como galeria de fotos, arquivos sonoros, indicações bibliográficas e acervo documental com registro de mortos e desaparecidos desse fato histórico (Figura 1). Por meio da animação, é possível observar fatos que ocorreram simultaneamente em locais distintos, o que facilita a compreensão do fato em sua totalidade. Por outro lado, em muitas abas 
da animação encontram-se excessivas quantidades de textos, limitando o usuário em grande parte à leitura tradicional.

Animação interativa "A Guerra do século 20" [Secretaria de Educação do Pará 2018] apresenta a cronologia do conflito, sendo possível visualizar os alojamentos e câmaras de gás do holocausto em diferentes perspectivas. Também conta com vídeos de depoimentos de vítimas, fotos, curiosidades e possui ainda cores e sons marcantes que são bastante atrativos para o usuário, como pode ser visto na Figura 2. A animação permite que o aluno participe como primeira pessoa durante o conflito, aumentando o nível de retenção do conteúdo.
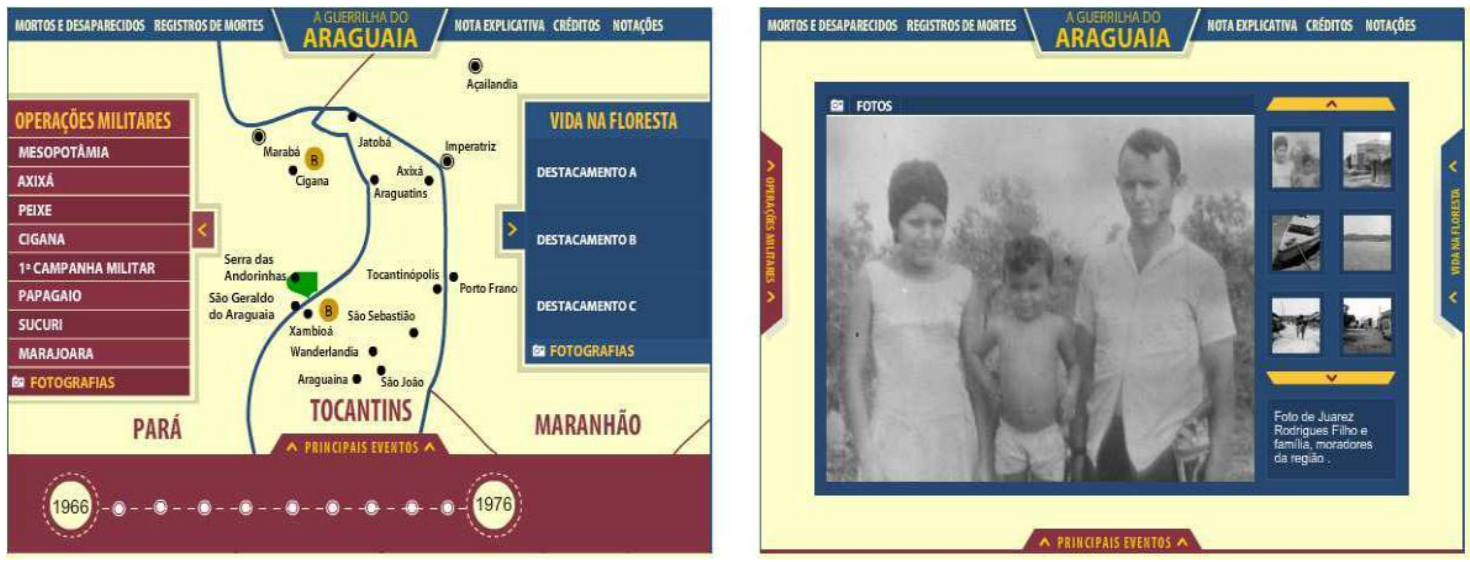

Figura 1. Animação interativa guerrilha do Araguaia.
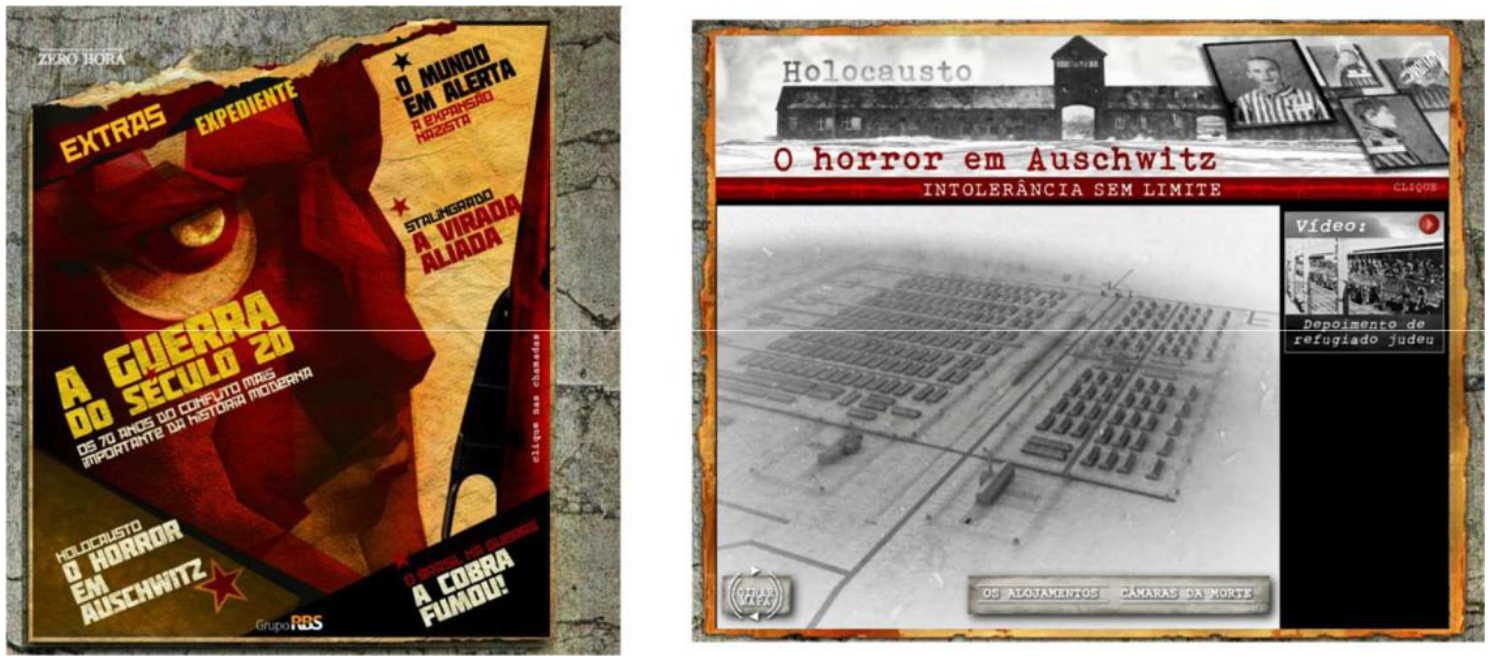

Figura 2. Animação interativa A guerra do século 20.

Estes exemplos de animações interativas exploram as informações e estimulam a curiosidade acerca da busca e descoberta de assuntos históricos. No entanto, observase escassez de animações interativas históricas para explorar o imaginário infantil e estimular o interesse pelo conhecimento de fatos do passado, em especial relacionado à História da Paraíba. 


\section{Metodologia}

De acordo com os conceitos de Waslawick (2014) a pesquisa foco deste artigo é caracterizada na área de computação como apresentação de algo diferente, pois apresenta um estudo no qual foi elaborado um material multimídia com características distintas aos encontrados para apoio à disciplina de História. Dentre as características, tem-se: abordar o tema História da Paraíba; utilizar personagens interativos para conduzir a história relatada; e prover atividade com desafios para o usuário. O processo de desenvolvimento ocorreu a partir da colaboração e troca de informações entre desenvolvedores e especialista em História da Paraíba, considerando também uma revisão bibliográfica baseada em fatos históricos que narram a História da Paraíba.

A especialista colaboradora do projeto foi uma educadora, escritora e historiadora, graduada em Licenciatura plena em História e pós-graduada em História da Paraíba, turismo e meio ambiente. Ela possui ampla experiência como professora de História da Paraíba, lecionando a disciplina há mais de 25 anos.

O processo técnico de elaboração da História da Paraíba em animações foi baseado em um processo simplificado de construção proposto por Wangenheim e Wangenheim (2012). Neste trabalho, as etapas foram divididas em: ativação, especificação e desenvolvimento, detalhadas a seguir.

Após a conclusão da animação, foi realizado um experimento em sala de aula. A aplicação da animação interativa foi realizada em duas turmas de $5^{\text {a }}$ ano do ensino fundamental de uma escola particular situada em João Pessoa. As turmas participantes foram selecionadas pela professora de História da escola, com base na adequação do assunto ministrado. $\mathrm{O}$ intuito dessa aplicação foi verificar a percepção da docente acerca do uso dessa animação em sala de aula, bem como observar a importância deste material como recurso motivacional de aprendizagem, verificando a interação dos alunos e docente com o conteúdo, por meio da animação.

\section{História da Paraíba em animações: passos de desenvolvimento}

A História da Paraíba é muito rica em fatos e curiosidades que envolvem batalhas, romances, costumes indígenas, expedições, traições e estratégias de guerra, de uma maneira que encanta seus espectadores. Uma forma de facilitar o entendimento é a utilização de mídias digitais que narram essas histórias.

Dentre o conteúdo de História da Paraíba, o foco de produção da atual animação interativa foi a representação midiática de parte da colonização da Paraíba, mais precisamente a tragédia de Tracunhaém, que resultou no desmembramento da capitania de Itamaracá. A seguir são apresentadas as etapas de ativação, especificação e desenvolvimento da animação.

\subsection{Etapa de ativação}

$\mathrm{Na}$ fase de ativação foram realizados os primeiros contatos com a especialista em História da Paraíba e as primeiras ideias foram lançadas. Ainda nessa fase, uma proposta de produto foi discutida e aprovada pela especialista, na qual foi definido que o público-alvo seriam alunos do ensino fundamental, que o modelo de material instrucional seria caracterizado como animação interativa e bem como o escopo do 
conteúdo a ser trabalhado, onde seria focado no período de colonização da Paraíba, especificamente a tragédia de Tracunhaém.

Essa tragédia foi importante porque, a partir deste fato histórico, houve o desmembramento da capitania de Itamaracá, originando dessa maneira a capitania real da Paraíba que viria mais tarde a se tornar o estado da Paraíba. Este recorte específico da História foi escolhido tendo em vista que é a partir dele que a História da Paraíba se inicia. Ainda na fase de ativação foi elaborado um storyboard (https://bit.ly/2KsDoWJ) que orientou as etapas seguintes ao processo de produção do material instrucional.

\subsection{Etapa de especificação}

A criação dos personagens históricos foi auxiliada por uma busca em repositórios gratuitos de licença livre. No repositório online Superpower, foram encontrados elementos gráficos que estavam alinhados ao tema ou que poderiam ser adaptados para utilização na animação interativa. Os personagens disponíveis do Superpower, além de alta qualidade, mostravam características semelhantes às personalidades envolvidas na tragédia de Tracunhaém.

Alguns personagens passaram por modificações a partir de uma ferramenta de autoria de imagens, com o intuito de caracterizar o personagem para o contexto da história retratada na animação. A Figura 3 mostra a mesclagem de componentes de dois personagens disponíveis no repositório, adicionando a pintura facial. A partir desse tratamento de imagem, pôde ser criado um novo personagem com características semelhantes ao índio narrado na História.

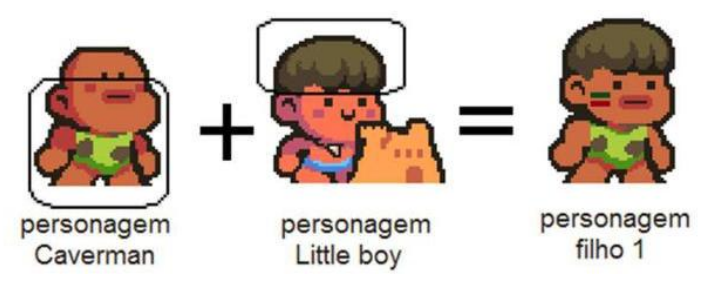

Figura 3. Adaptação dos personagens. Fonte: próprio autor.

$\mathrm{Na}$ fase de especificação também foram definidos quais personagens (no contexto da tragédia de Tracunhaém) seriam utilizados para participar do enredo, com base na importância para a narração dos fatos. Estes personagens são apresentados na Figura 4.

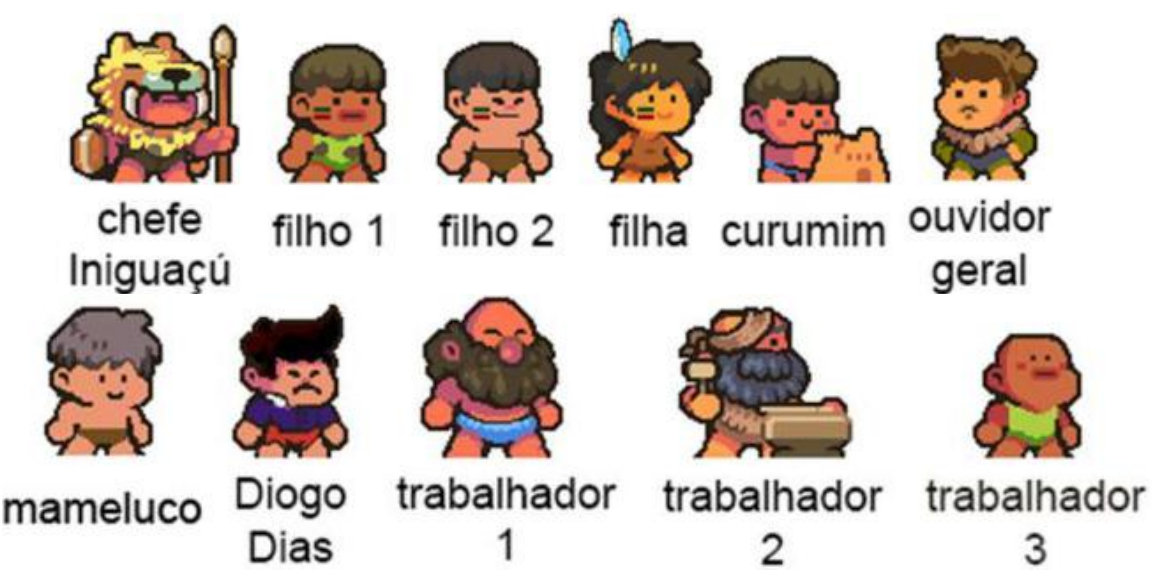

Figura 4. Personagens utilizados no projeto. Fonte: próprio autor. 


\subsection{Desenvolvimento.}

O desenvolvimento da animação foi realizado por meio da ferramenta Construct 2, utilizando o paradigma de programação orientada a eventos [Malacarne 2001]. No decorrer da fase de desenvolvimento foram construídas e implementadas todos os diálogos, montagem do cenário e sincronização das animações através de sprites [Silva et al. 2009].

A Figura 5 mostra uma sequência de sprites para representar a caminhada da filha do chefe Iniguaçú. A partir da figura, percebe-se que para reproduzir uma simples animação de caminhada, são necessárias diferentes sprites exibidas em sucessão e que possuem pequena variação de movimento para simular a caminhada. Esse procedimento foi necessário para todos os personagens e objetos que proponham movimento em alguma cena da animação.
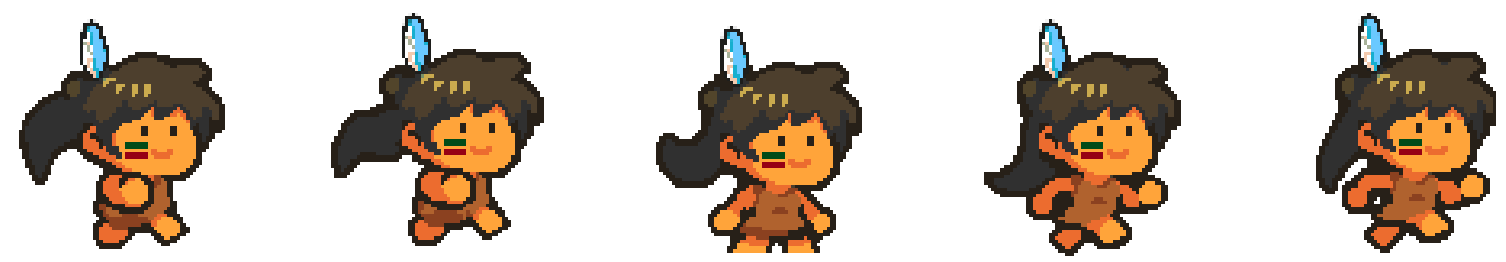

Figura 5. Sprite da caminhada da filha do chefe Iniguaçú.Fonte: próprio autor.

Todo processo de desenvolvimento seguiu a proposta pré-estabelecida no storyboard, sendo ajustado com base no feedback da especialista ao longo da produção. Cenas da animação finalizada podem ser visualizadas por meio da Figura 6 e 7. A Figura 6 mostra um trecho de pensamento do personagem Mameluco ao se apaixonar pela índia. Na Figura 7 o aluno pode interagir com a animação através do personagem que precisa se deslocar para chegar no destino.

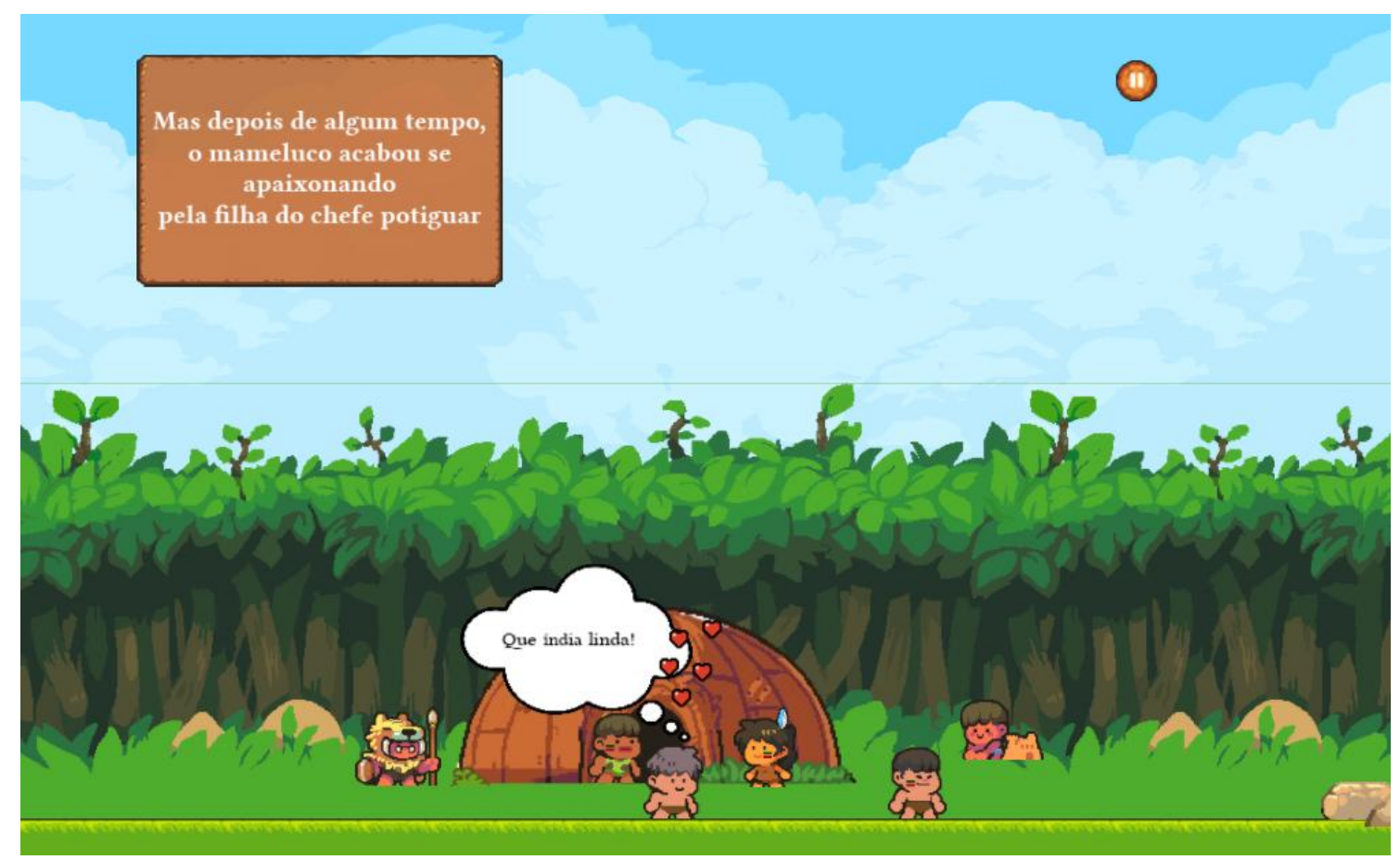

Figura 6. Cenário com personagens no momento de encontro entre mameluco e índia. Fonte: próprio autor. 


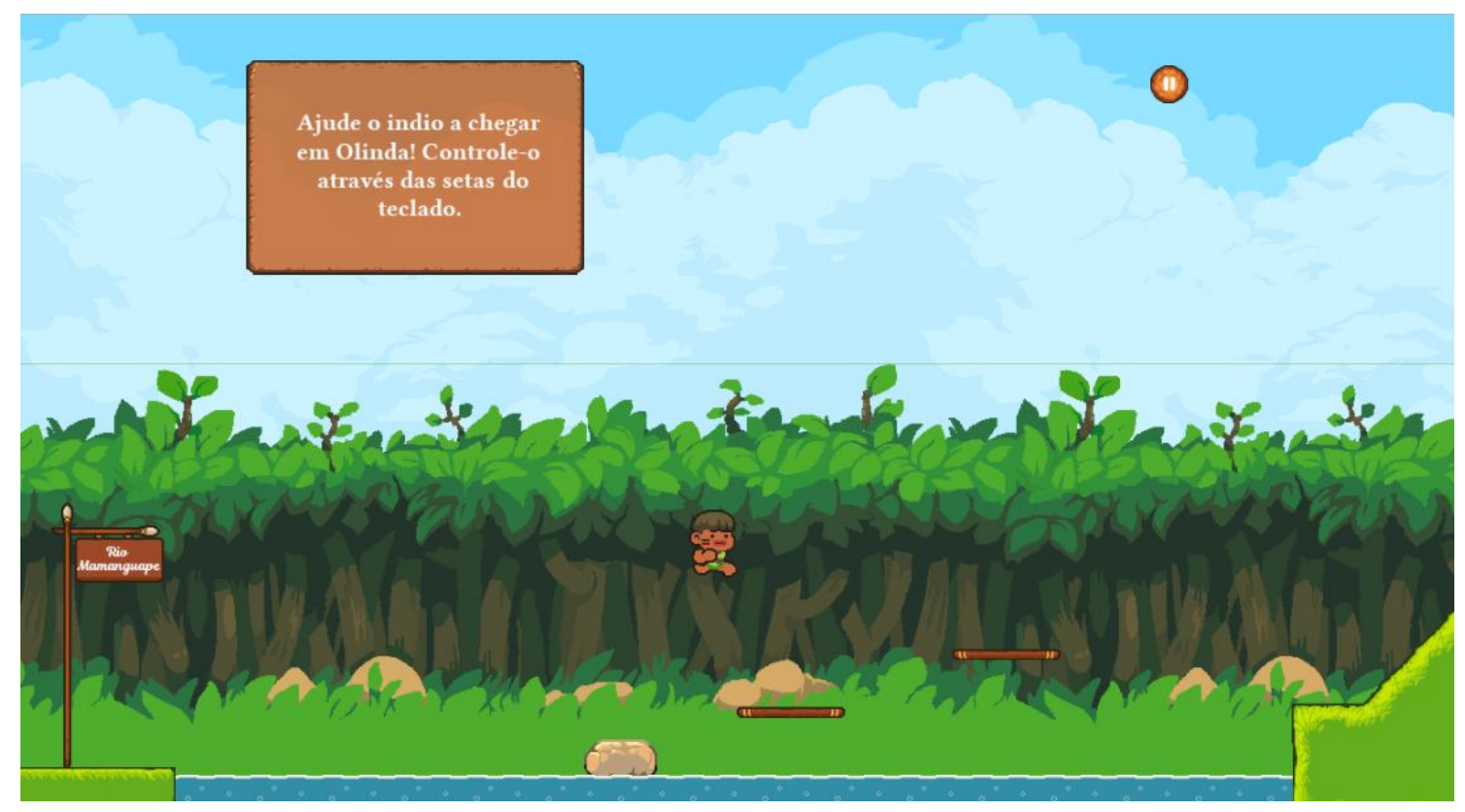

Figura 7. Cenário em momento de interação do usuário. Fonte: próprio autor.

A animação desenvolvida se encontra disponível no endereço eletrônico $<$ paraibaemanimacoes.netlify.com> e recomenda-se que seja visualizada através de computador, pois é necessário o uso teclado para avançar as etapas.

\section{Experiência em sala de aula}

Como apresentado na seção 3, a aplicação da animação interativa foi realizada em duas turmas do $5^{\circ}$ ano. A primeira turma possuía 33 alunos e a segunda 27 alunos, todos com faixa etária entre 10-12 anos. A aplicação da animação aconteceu durante uma aula de História, pela própria docente. Na aula, a animação foi utilizada como ferramenta de apoio ao ensino do conteúdo. A docente contava a história sobre a tragédia de Tracunhaém seguindo o fluxo da animação que estava sendo exibida em uma TV. Já no início da apresentação, observou-se a empolgação das crianças ao perceberem o uso da animação para representar a história contada pela professora.

Ao longo da narração, os alunos interagiram com a professora através de perguntas e deduções, demonstrando empolgação com a metodologia aplicada. Como a escola dispunha de apenas um computador disponível em sala de aula, os alunos eram convidados individualmente a utilizar a animação (Figura 8). No momento que utilizavam a ferramenta, observou-se a atenção no conteúdo, ao se colocarem no lugar do personagem, que precisava se deslocar da Serra da Copaoba até Olinda, ao mesmo tempo em que a professora ia narrando os fatos e revelando curiosidades da época.

A professora, em seus comentários após a aplicação, destacou que um de seus alunos que sofre um grande problema de atenção, apresentou um comportamento diferente do seu cotidiano, conseguindo interagir com a ferramenta e concluir todos os desafios da animação. Outro fato observado foi que alguns alunos sentiram dificuldade em passar pelos desafios interativos com obstáculos, nos quais eram exigidos que o personagem pulasse e corresse para avançar a animação. 


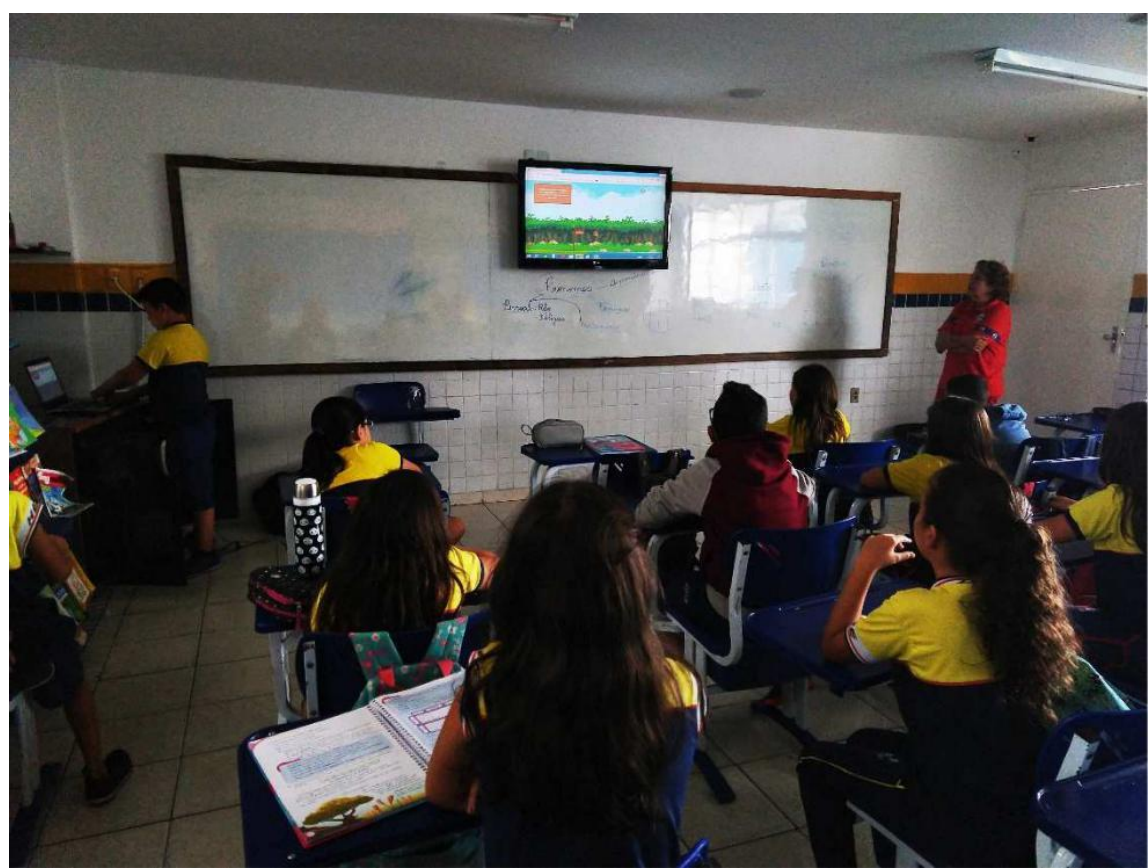

Figura 8. Interação de alunos com ferramenta. Fonte: próprio autor.

Ao final da aula foi realizada pela professora uma roda de diálogo na qual os alunos relataram suas percepções acerca do conteúdo abordado, com o intuito de verificar o nível de fixação do conteúdo. $\mathrm{Na}$ roda de diálogo os alunos conseguiram narrar voluntariamente a história com suas palavras e alguns alunos ainda manifestaram interesse de se posicionar diante da turma para contar os fatos, como pode ser visualizado na Figura 9. Tal fato sugere que o uso da animação, além de ter captado a atenção do aluno durante a aula, auxiliou no entendimento da história ao ponto de alguns discentes se sentirem seguros para se expressar diante dos colegas.

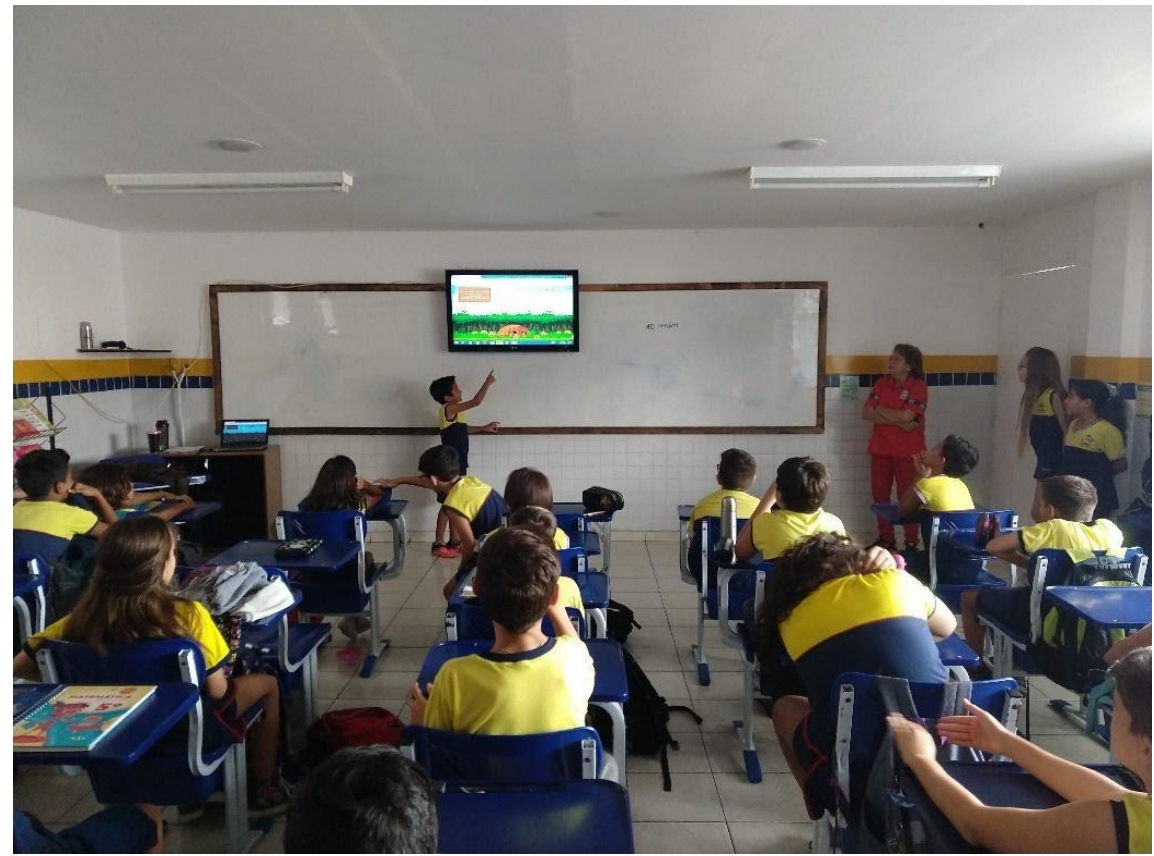

Figura 9. Aluno narrando os fatos a partir de sua percepção. Fonte: próprio autor. 


\section{Considerações}

O desenvolvimento de animações é um processo que envolve muitas áreas do conhecimento como programação, designer gráfico e roteiros, integrando elementos em um sistema multimídia alinhado ao fato de ter base em acontecimentos históricos.

Por meio da aplicação da animação interativa em sala de aula, observou-se que a ferramenta colaborou para o aprendizado dos alunos, facilitando a compreensão e retenção do conteúdo, tornando a aula atrativa e divertida. Sob o olhar da professora das turmas participantes o uso da ferramenta foi considerado "muito interessante! muito didático e assim de muita precisão sob o olhar do aluno. Quando terminou eles já sabiam de tudo, tudo detalhado o que eu tinha tanta dificuldade de explicar nas minhas aulas".

Pretende-se, como trabalho futuro, avaliar os aspectos pedagógicos e de usabilidade da animação junto a outros professores de história, de modo a coletar sugestões de melhorias e verificar sua eficácia como instrumento de apoio ao ensino. A partir desta ferramenta, também pretende-se como trabalho desenvolver uma série de animações que contemplem toda a história da colonização da Paraíba, incluindo o desmembramento da capitania de Itamaracá e as 5 expedições que resultaram na fundação da cidade de Nossa Senhora das Neves.

\section{Referências}

Abusamra, V., Cartoceti, R., Raiter, A. G. e Ferreres, A. R. (2008) "Uma perspectiva cognitiva no estudo da compreensão de textos", In Psico, 39(3), 13.

da Cruz Alves, N., von Wangenheim, C. G., Rodrigues, P. E., Hauck, J. C. R., e Borgatto, A. F. (2016) "Ensino de computação de forma multidisciplinar em disciplinas de história no ensino fundamental-um estudo de caso", In Revista Brasileira de Informática na Educação, 24(3), 31.

Malacarne, J. (2001) "Ambiente visual para Programação distribuída em java", 155 f. Dissertação (Mestrado em Computação) - Universidade Federal do Rio Grande do Sul, Porto Alegre.

Memórias Reveladas. (2010) "Guerrilha do Araguaia", http://www.memoriasreveladas.gov.br/index.php/multimidias, Abril.

Oliveira, P. (2017) "Objetos de Aprendizagem de simulação e animação para o ensino de Biologia: uma análise quanti-qualitativa". In Revista Tecnologias na EducaçãoAno, 9.

Schimiguel, J., Sanches, W. E., Andreasi, M. R., e de Siqueira, P. H. (2013) "A aplicação de animações no ensino de física". In RENOTE-Revista Novas Tecnologias na Educação, 11(1).

Secretaria de Educação do Pará. (2020) "Segunda Guerra Mundial", Paraná, http://www.historia.seed.pr.gov.br/modules/links/links.php?ini=S\&categoria=12, Abril. 
Silva, M. P. R., Costa, P. D. P., Prampero, P S. e Figueiredo, V. A. (2009) "Elementos de Computação Gráfica utilizados em Jogos Digitais 2D", Universidade estadual de Campinas, Campinas.

Tavares, R. (2005) "Animações interativas e mapas conceituais", XVI Simpósio Nacional de Ensino de Física.

Tversky, B., Morrison, J. B., e Betrancourt, M. (2002) "Animation: can it facilitate?", In International journal of human-computer studies, 57(4), 247-262.

Wangenheim, C. G. von, e Wangenheim, A. von (2012), Ensinando computação com jogos, Bookess Editora, Florianópolis, SC, Brasil.

Wazlawick,R,S. (2014) "Metodologiade pesquisaparaciênciada computação", Elsevier.

Xiao, L. (2013) "Animation trends in education". In International Journal of Information and Education Technology, 3(3), 286. 